\title{
Highlights
}

- Redox state of extracellular vesicles (EVs) was detected by dual labelling

- Monocyte surface thiols were found to be enhanced after stimulation

- In contrast, surface thiols of secreted EVs were decreased

- Overoxidised Prdx was detected in EVs

- EV secretion thus, may serve as an antioxidant mechanism 


\section{HEALTHY STATE}
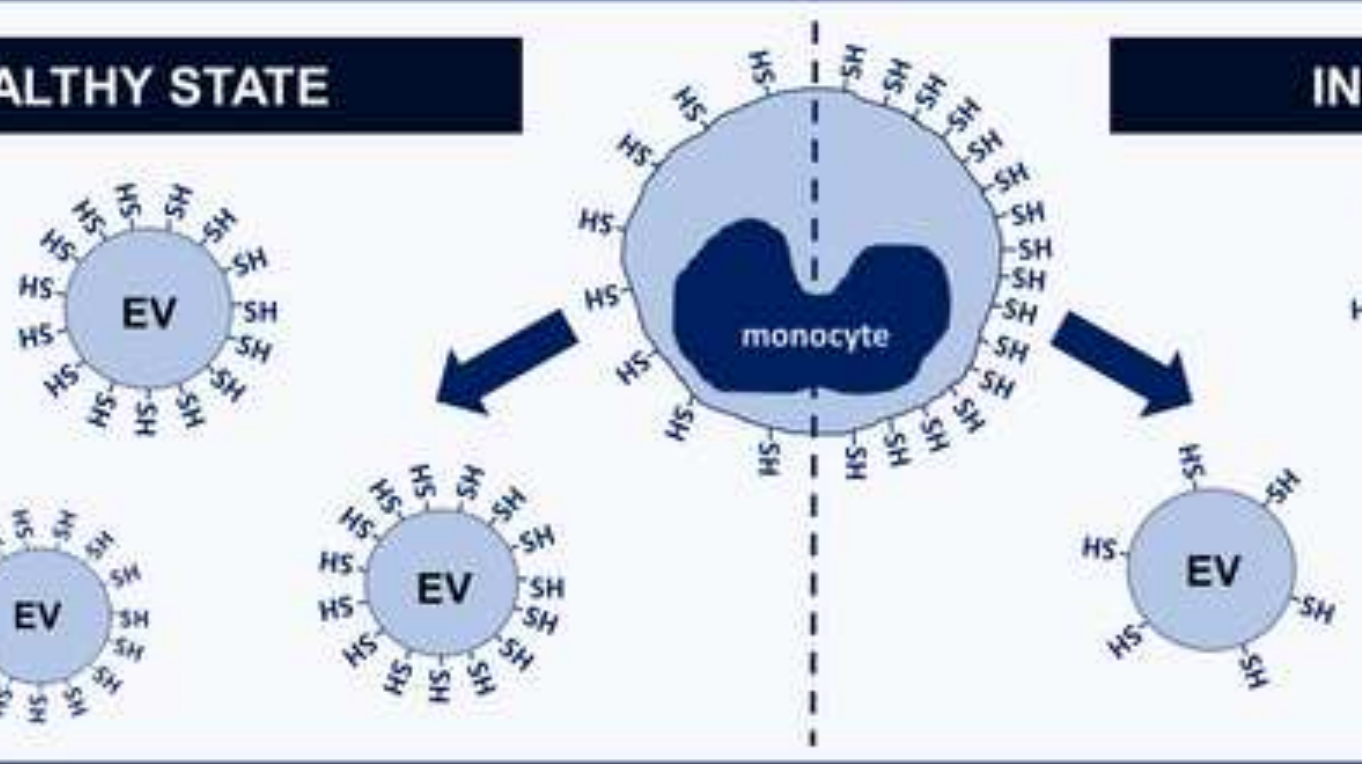

\section{INFLAMMATION}
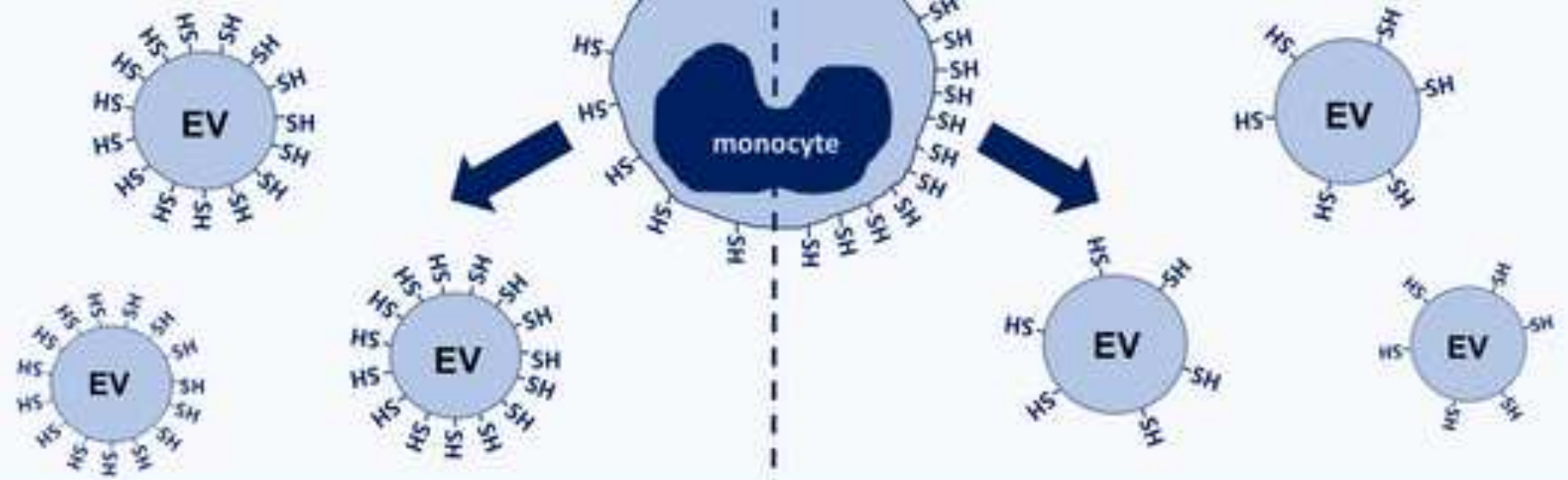

DUAL LABELLING FOR ANALYSIS OF SURFACE THIOLS OF BLOOD-DERIVED EXTRACELLULAR VESICLES

DyLight $\circledast$ Maleimide

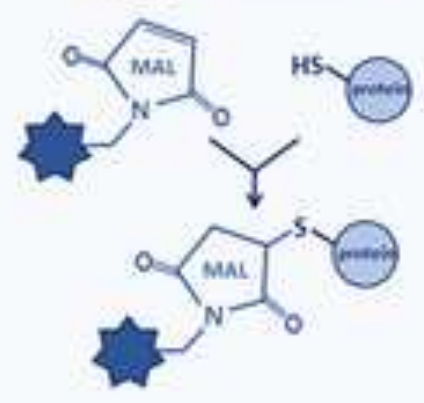

EV-specific antibody/stain

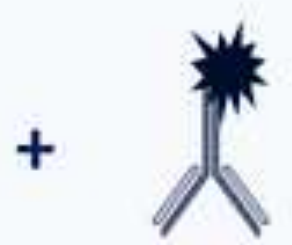

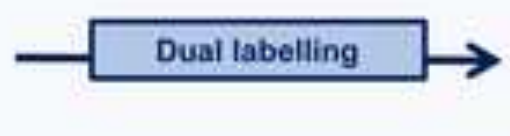

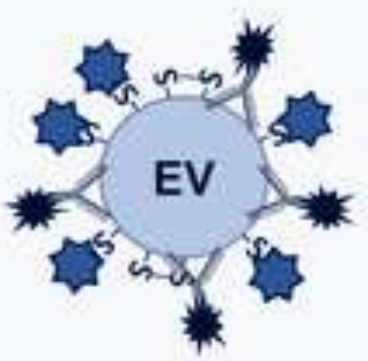

Flow Cytometry

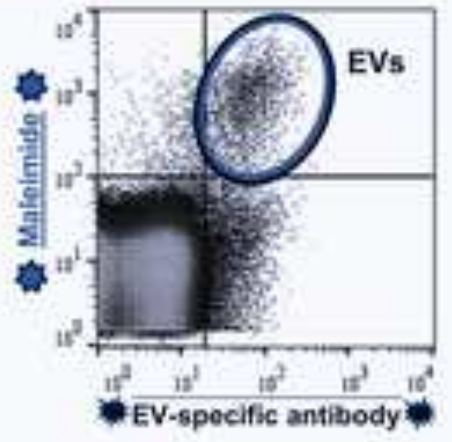




\section{Monocyte activation drives preservation of membrane thiols by} promoting release of oxidised membrane moieties via extracellular vesicles extracellular vesicles

KÉ Szabó-Taylor ${ }^{\mathrm{a},{ }^{*} \S}$, EÁ Tóth ${ }^{\mathrm{a}, \S}$, AM Balogh ${ }^{\mathrm{a}}$, BW Sódar ${ }^{\mathrm{a}}$, L Kádár $^{\mathrm{a}}, \mathrm{K}$ Pálóczi $^{\mathrm{a}}, \mathrm{N}$ Fekete $^{\mathrm{a}}$, A Németh ${ }^{\mathrm{a}}, \mathrm{X}$ Osteikoetxea ${ }^{\mathrm{a}}, \mathrm{KV}$ Vukman $^{\mathrm{a}}, \mathrm{M}$ Holub $^{\mathrm{a}}$, É Pállinger ${ }^{\mathrm{a}}$, Gy Nagy ${ }^{\mathrm{a}, \mathrm{b}}$, PG Winyard ${ }^{c}$ and EI Buzás ${ }^{\mathrm{a}}$

${ }^{a}$ Semmelweis University, Department of Genetics, Cell- and Immunobiology, 1089, Budapest, Nagyvárad tér 4, Hungary

${ }^{\mathrm{b}}$ Semmelweis University, Department of Rheumatology, $3{ }^{\text {rd }}$ Department of Internal Medicine, 1023, Budapest, Hungary

'University of Exeter Medical School, EX1 2LU, St Luke's Campus, Heavitree Road, Exeter, United Kingdom

$\S$ These authors contributed equally to this work

*Correspondence to: Semmelweis University, Dept. of Genetics, Cell- and Immunobiology, 1085, Budapest, Üllői út 26, Hungary, Phone: +36 1210 2930/56234, E-mail address: szabotaylor.katalin@med.semmelweis-univ.hu 


\section{Highlights}

- Redox state of extracellular vesicles (EVs) was detected by dual labelling

- Monocyte surface thiols were found to be enhanced after stimulation

- In contrast, surface thiols of secreted EVs were decreased

- Overoxidised Prdx was detected in EVs

- EV secretion thus, may serve as an antioxidant mechanism 


\section{Abstract}

The redox state of cellular exofacial molecules is reflected by the amount of available thiols. Furthermore, surface thiols can be considered as indicators of immune cell activation. One group of thiol containing proteins, peroxiredoxins, in particular, have been associated with inflammation.

In this study, we assessed surface thiols of the U937 and THP1 monocyte cell lines and primary monocytes in vitro upon inflammatory stimulation by irreversibly labelling the cells with a fluorescent derivative of maleimide. We also investigated exofacial thiols on circulating blood mononuclear cells in patients with rheumatoid arthritis and healthy controls. When analysing extracellular vesicles, we combined thiol labelling with the use of antibodies to specific $\mathrm{CD}$ markers to exclude extracellular vesicle mimicking signals from thiol containing protein aggregates. Furthermore, differential detergent lysis was applied to confirm the vesicular nature of the detected extracellular events in blood plasma.

We found an increase in exofacial thiols on monocytes upon in vitro stimulation by LPS or TNF, both in primary monocytes and monocytic cell lines $(\mathrm{p}<0.0005)$. At the same time, newly released extracellular vesicles showed a decrease in their exofacial thiols compared with those from unstimulated cells $(\mathrm{p}<0.05)$. We also found a significant elevation of surface thiols on circulating monocytes in rheumatoid arthritis patients $(\mathrm{p}<0.05)$ and newly released extracellular vesicles of isolated $\mathrm{CD}_{1} 4^{+}$cells from rheumatoid arthritis patients had decreased thiol levels compared with healthy subjects $(\mathrm{p}<0.01)$. Exofacial peroxiredoxin 1 was demonstrated on the surface of primary and cultured monocytes, and the number of peroxiredoxin 1 positive extracellular vesicles was increased in rheumatoid arthritis blood plasma $(\mathrm{p}<0.05)$. Furthermore, an overoxidised form of peroxiredoxin was detected in extracellular vesicle-enriched preparations from blood plasma.

\footnotetext{
Abbreviations: CRP: C-reactive protein, DAS: disease activity score, DTNB: 5,5-dithiobis-(2-nitrobenzoic acid), EF thiol: exofacial thiol, EV: extracellular vesicle, HS: healthy subject, LDL: Low-density lipoprotein, LPS: lipopolysaccharide, Mal: maleimide, PBMC: peripheral blood mononuclear cells, PBS: phosphate buffered saline, PDI: protein disulfide isomerase, PFP: platelet-free plasma, Prdx 1: peroxiredoxin 1, PVDF: polyvinylidene difluoride, RA: rheumatoid arthritis, SDS-PAGE: polyacrylamide gel electrophoresis, TNF: tumor necrosis factor
} 
Our data show that cell surface thiols play a protective role and reflect oxidative stress resistance state in activated immune cells. Furthermore, they support a role of extracellular vesicles in the redox regulation of human monocytes, possibly representing an antioxidant mechanism.

\section{Keywords}

exofacial thiols, peroxiredoxin 1, maleimide, inflammation, extracellular vesicle

\section{Introduction}

Redox homeostasis is essential for the maintenance of cell physiology. This homeostasis is maintained not only by intracellular, but also by extracellular and cell surface redox molecular mechanisms. However, plasma membrane surface redox mechanisms received relatively little attention in the past. Immune reactions are characterised by substantial redox changes. Furthermore, immune cell activation and proliferation are associated with an increase in the levels of cell surface thiols [1]. For example, $\mathrm{CD}^{+} \mathrm{T}$ cells upregulate their surface thiols upon specific TCR stimulation before their cell proliferation starts [2]. This presumably serves as a protective mechanism to prevent the oxidation of sensitive surface proteins. A sustained upregulation of cell surface thiols on effector $\mathrm{CD}^{+} \mathrm{T}$ cells is also observed during viral infection [2]. Increase in surface thiol levels (a process dependent on cell surface protein disulfide isomerase) is also necessary for increased proliferation of human lymphocytes [3]. Importantly, the increase in surface thiol levels may even enhance disease susceptibility (as evidenced for example in Dark Agouti rats in which it has been shown to enhance susceptibility to develop severe arthritis) [4].

Extracellular vesicles (EVs) are phospholipid bilayer membrane enclosed subcellular structures released by all types of cells $[5,6]$. EVs are characterised by substantial heterogeneity; the best characterised categories include exosomes $(30-150 \mathrm{~nm})$, microvesicles/microparticles $(100-1000 \mathrm{~nm})$ and large EVs such as apoptotic bodies 
$(>1000 \mathrm{~m})[5,6]$.

A role for thiol groups in extracellular vesicle (EV) release has been first demonstrated when

Dachary-Pringent and colleagues showed that blocking of thiols prevented microparticle/microvesicle release by platelets [7]. Other studies also showed a link between redox processes and EV release (reviewed in [8]).

The role of extracellular vesicles (EVs) in arthritis has been increasingly recognised [6]. However, the redox state and redox aspects of EVs in RA have not yet been studied.

In this paper, we detect for the first time the levels of EV thiols in a releasing cell typespecific manner. Furthermore, we show a decrease in surface thiol levels of freshly released EVs, in sharp contrast with the elevation of surface thiols of the activated mother cells. Based on these data, we propose that activated cells use EV-secretion as a tool to rapidly enhance their plasma membrane thiol levels by shedding oxidised (less reduced) plasma membrane patches in the form of EVs. This mechanism could possibly serve as part of the cells' antioxidant defence system.)

\section{Materials and Methods}

\section{Sample collection and subjects}

After obtaining ethics permission from the Hungarian Scientific and Research Ethics Committee and informed consent from the subjects, blood samples were collected from RA patients and healthy subjects (HS) in EDTA for monocyte isolation and detection and acid citrate dextrose (ACD-A) anticoagulation tubes for EV assessment (both from Greiner). ACD-A tubes were used to prevent in vitro vesiculation of blood cells [9]. Anticoagulated blood samples were centrifuged first at $400 \mathrm{~g}$ for 20 minutes, and then twice at $3000 \mathrm{~g}$ for 15 minutes to remove platelets. The supernatant was snap frozen in liquid nitrogen and kept at $80{ }^{\circ} \mathrm{C}$ in aliquots, as platelet-free plasma (PFP). Peripheral blood mononuclear cells (PBMCs) were isolated using Ficoll (Sigma) gradient separation. PBMCs were lysed for Western blotting experiments and kept at $-80{ }^{\circ} \mathrm{C}$. 
Altogether, 71 patients with RA, with a median age of 59.5 years (range: 29-88 years) were involved in this study. The patients were treated at the Department of Rheumatology, Semmelweis University (Budapest, Hungary). The median DAS28 score was 3.14 (range: 0.87.08) and the median CRP value was $4 \mathrm{mg} / \mathrm{L}$ (range: 0-603 $\mathrm{mg} / \mathrm{L}$ ). Only RA patients diagnosed on the basis of the American College of Rheumatology criteria [10, 11] were included. The median age of the 54 healthy subjects was 42 years (range: 20-71 years).

\section{Detection of cell surface thiol levels using flow cytometry}

EDTA anticoagulated whole blood $(1 \mathrm{~mL})$ from RA patients $(\mathrm{n}=15)$ and healthy subjects $(\mathrm{n}=10)$ was washed once in Hanks balanced salt solution (Sigma) and incubated in $50 \mu \mathrm{M}$ DyLight-488 maleimide (ThermoFisher Scientific) for 20 minutes at room temperature. Subsequently, the samples were washed twice and incubated with anti-CD3-APC (BD Pharmingen), anti-CD11c-APC (BioLegend) / anti-CD14-APC (SONY) / anti-CD14-PerCPCy5.5 (BD Biosciences) or anti-CD19-PerCP-Cy5.5 (BD Biosciences) antibodies. Following antibody labelling, the samples were treated with FACSLyse Solution (BD) for 10 min at $4{ }^{\circ} \mathrm{C}$ and measured using a FACSCalibur Flow Cytometer (Beckton-Dickinson). Cellquest software (BD Biosciences) and by FlowJo software (Treestar, Ashland, OR) were used for flow cytometer data analysis.

\section{In vitro stimulation of monocytes by lipopolysaccharide (LPS) and tumour necrosis factor (TNF) and in vitro EV collection}

Peripheral blood samples were collected from healthy subjects $(n=8)$ in EDTA anticoagulant tubes. In order to avoid exposure of blood to ambient oxygen, $100 \mathrm{ng} / \mathrm{mL}$ LPS (L6529 O55:B5 E coli Sigma) was injected with a needle and syringe directly into the Vacuette ${ }^{\circledR}$ collection tube without abolishing vacuum, and whole blood samples were incubated for 90 min at $37{ }^{\circ} \mathrm{C}$. Following the incubation period, exofacial thiol levels of $\mathrm{CD} 11 \mathrm{c}^{+} / \mathrm{CD} 14^{+}$ monocytes were measured as described above.

U937 and Thp1 monocytes were seeded at $0.5-1 \times 10^{6}$ cells $/ \mathrm{mL}$ serum-free RPMI medium. The cells were treated with $1 \mu \mathrm{g} / \mathrm{mL}$ or $100 \mathrm{ng} / \mathrm{mL}$ LPS (L6529 O55:B5 E. coli Sigma) or with 10 
$\mathrm{ng} / \mathrm{mL}$ human TNF (Sigma), and were incubated for $90 \mathrm{~min}$ at $37{ }^{\circ} \mathrm{C}$. The cells were subsequently washed with phosphate buffered saline (PBS), labelled with DyLight-488 maleimide at a $25 \mu \mathrm{M}$ concentration. After an incubation period of $15 \mathrm{~min}$ at $4{ }^{\circ} \mathrm{C}$ and an additional washing step, levels of exofacial thiols were detected using flow cytometry.

EVs from the 90 minutes conditioned media of LPS-treated U937 monocytes were collected by spinning the supernatant at $300 \mathrm{~g}$ for $5 \mathrm{~min}$, followed by 2,000 g $20 \mathrm{~min}$ and 20,000 $\mathrm{g}$ for $40 \mathrm{~min}$. The final pellet was resuspended in $40 \mu \mathrm{L}$ PBS and incubated with $25 \mu \mathrm{M}$ DyLight488 Mal for $20 \mathrm{~min}$. Subsequently, the samples were washed and measured using flow cytometry.

\section{Isolation of CD14 positive cells from peripheral blood and collection of EV-containing conditioned media}

Peripheral blood monocytes from RA patients and healthy subjects were isolated with the EasySep Human CD14 Positive Selection Kit (Stemcell Technologies) according to the manufacturer's instruction. Briefly, peripheral blood samples were collected from healthy subjects $(n=5)$ and rheumatoid arthritis patients $(n=6)$ in EDTA anticoagulated tubes. PBMCs were isolated using Ficoll (Sigma) gradient separation. The PBMCs were then mixed with an anti-CD14 antibody cocktail and specific magnetic nanoparticles. Subsequently, the mixture was washed and $\mathrm{CD} 14^{+}$cells were isolated with the aid of a magnet. Cell viability was assessed using trypan blue staining and only samples with more than $95 \%$ cell viability were used for downstream experiments. The CD14 positivity of cells was proved using flow cytometry.

Cells were then seeded at $0.5-1 \times 10^{6}$ cells $/ \mathrm{mL}$ concentration in RPMI medium containing $10 \%$ EV-free fetal bovine serum. After an incubation period of 90 minutes at $37{ }^{\circ} \mathrm{C}$, EVs were collected from the supernatant by spinning the supernatant at $300 \mathrm{~g}$ for $5 \mathrm{~min}$, followed by 2,000 g $20 \mathrm{~min}$ and 16,100 g for $40 \mathrm{~min}$. The final pellet was resuspended in $40 \mu \mathrm{L}$ PBS and incubated with $25 \mu \mathrm{M}$ DyLight-488 Mal for 20 minutes. Subsequently, the samples were washed and the thiols levels of EVs were measured with a FACSCalibur Cytometer. EV gate was established using Megamix (Biosytex) and silica beads ( $1 \mu \mathrm{m}$ Silica Beads Fluo-Green) 
(Kisker, Steinfurt, Germany) as we described earlier [12, 13]. After recording, samples were treated with $0.1 \%$ Triton X-100 and only Triton-sensitive events were considered genuine EVs [12].

\section{Detection of thiol levels in human blood plasma using an Ellman's assay}

PBS $(80 \mu \mathrm{L})$ was added to plasma samples $(100 \mu \mathrm{L})$ in the wells of a 96 well plate (Nunc, ThermoFisher Scientific). Next, $20 \mu \mathrm{L} 10 \mathrm{mM}$ 5,5-dithiobis-(2-nitrobenzoic acid) (DTNB) reagent (Pierce) dissolved in cc. methanol, was added to each well. After an incubation period of $15 \mathrm{~min}$ at room temperature, optical densities of the wells were measured at $412 \mathrm{~nm}$ using a Labsystems Multiskan MS Spectrophotometer. For each sample, a blank was also measured, and its optical density was subtracted as background. A standard curve was established using different dilutions of a cysteine standard (Pierce) in PBS and the concentration of thiols was expressed as $\mu \mathrm{M}$ cysteine equivalent $/ 100 \mu \mathrm{L}$ blood plasma.

\section{Labelling of EVs with annexin-V, antibodies to CD markers and DyLight maleimide}

For annexin-V labelling of EVs, annexin-V-FITC or APC (BD Biosciences) (5 $\mu \mathrm{L})$ was added to plasma samples $(50 \mu \mathrm{L})$ and incubated for $5 \mathrm{~min}$ at room temperature. After the addition of $1 \mathrm{~mL}$ annexin-binding buffer $\left(5 \mathrm{mM} \mathrm{CaCl}_{2}\right.$ solution in deionized water), the samples were spun at $20,500 \mathrm{~g}$ for $40 \mathrm{~min}$ at room temperature. The supernatant was discarded and the pellet was resuspended in $450 \mu \mathrm{L}$ annexin-binding buffer. EVs were labelled using anti-CD9-FITC (Sigma) and anti CD-63-PE (Sigma) antibodies. EVs were also tested using antibodies to platelets (anti-CD41a- FITC or APC (BD Biosciences)), endothelial cells (anti-CD105-FITC, anti-CD144-PE and anti-CD146-PE), erythrocytes (anti-glycophorin A-FITC) and monocytes (anti-CD14-PE) (all from BD Biosciences). FITC and PE-labelled isotype controls were used (BD Biosciences). For staining with antibodies, plasma samples $(5 \mu \mathrm{L})$ were diluted in PBS (45 $\mu \mathrm{L})$ and the relevant labelled antibody $(1 \mu \mathrm{L})$ was added. The samples were incubated for 30 min at $4{ }^{\circ} \mathrm{C}$, followed by the addition of $450 \mu \mathrm{L}$ PBS.

Redox-specific double labelling of plasma EVs was carried out as follows: PFP samples (20 $\mu \mathrm{L}$ ) were incubated with DyLight-488 or -633 maleimide (ThermoFisher Scientific) at a final 
concentration of $50 \mu \mathrm{M}$ for 10 minutes at room temperature. Following the incubation period, $500 \mu \mathrm{L}$ filtered (through a $0.2 \mu \mathrm{M}$ pore size filter) PBS or annexin-binding buffer was added to the samples, and they were spun at $20,500 \mathrm{~g}$ for 40 minutes. The supernatant was discarded using a syringe and the dry pellet was resuspended in PBS or annexin-binding buffer $(50 \mu \mathrm{L})$. Then the samples were labelled with fluorochrome-conjugated antibodies or annexin- $\mathrm{V}$, as described above. Beads (PKH26-latex beads, Sigma) with known particle number were added, and the samples were analysed by flow cytometry for 60 seconds.

\section{Western blot analysis of peroxiredoxins}

For the detection of exofacial Prdx 1 of cultured monocytes, we isolated exofacial proteins from LPS-treated (100 ng/mL, 24 hours) U937 cells using a Pierce cell surface protein isolation kit (according to the manufacturer's instructions). Next, the isolated cell surface proteins were separated on a reducing 4-20\% gradient SDS-PAGE gel (ThermoFisher Scientific), then blotted onto a PVDF (polyvinylidene difluoride) membrane, incubated in 1:1,000 with primary antibodies against Prdx 1 (AbFrontier) and protein disulfide isomerase (PDI, Cell Signalling), the latter serving as a positive control. An HRP-labelled rabbit anti mouse antibody (Sigma) was used as secondary antibody $(1: 10,000)$. Antibody reactivity was detected with enhanced chemiluminescence (ThermoFisher Scientific) and a Chemidoc Digital Imaging System (Bio-Rad). Lysates of healthy PBMCs were also used as a positive control for Prdx 1.

For the detection of intracellular Prdx 1 in PBMCs, cells were isolated as described above, and the pellet was lysed in non-reducing Laemmli buffer containing $100 \mathrm{mM}$ maleimide. The method is based on the fact that reduced Prdx 1 (where the redox active peroxidatic cysteine is in the thiol state) is in monomeric form while oxidised Prdx 1 is dimeric. In the dimeric state, the peroxidatic and resolving cysteines of two Prdx 1 molecules build a disulfide bridge. Non-reducing Western blotting conserves and reveals this difference in the different redox states [14]. Lysates containing $20 \mu \mathrm{g}$ protein, as determined by MicroBCA (ThermoFisher Scientific) were resolved on a non-reducing 4-20\% gradient gel, blotted and incubated with a mouse antibody to Prdx 1 (AbFrontier) in 1:1,000. Membrane-bound primary antibodies were detected as described above. 
To detect the oxidation state of peroxiredoxins in EV-enriched preparations of PFP, PFP was centrifuged for $40 \mathrm{~min}$ at 20,500 g, and washed subsequently with PBS. The clean pellets were lysed in Laemmli buffer, and equivalent protein amounts $(2 \mu \mathrm{g})$ were resolved on a reducing 4-20\% gradient gel, blotted and incubated with a mouse monoclonal antibody to overoxidised Prdx (AbFrontier) (1:500) and membrane-bound antibodies were detected as described above.

\section{Detection of peroxiredoxin 1 in primary monocytes using flow cytometry}

For assessment of cells, EDTA anticoagulated whole blood $(1 \mathrm{~mL})$ from RA patients $(\mathrm{n}=10)$ and healthy subjects $(\mathrm{n}=14)$ was incubated with anti-CD14-PerCP-Cy5.5 (BD Biosciences) /anti-CD14-APC (SONY) and anti-Prdx 1-Alexa488 (Bioss) antibodies for 20 min. Following antibody labelling, the samples were treated with FACSLyse Solution (BD) for 10 min at $4{ }^{\circ} \mathrm{C}$ and measured using a FACSCalibur Flow Cytometer. For intracellular Prdx 1 labelling, cells were first fixed with $4 \%$ PBS-buffered paraformaldehyde and permeabilised with $0.1 \%$ saponin followed by labelling with anti-CD14-PerCp-Cy5.5 antibody.

\section{Detection of peroxiredoxin 1, 2 and thioredoxin 1 on EVs using flow cytometry}

For assessment of EVs, PFP samples $(100 \mu \mathrm{L})$ were incubated with DyLight-488 maleimide at a final concentration of $200 \mu \mathrm{M}$ for $10 \mathrm{~min}$ at room temperature. Subsequently, $500 \mu \mathrm{L} 0.2$ $\mu \mathrm{m}$-filtered PBS was added to the samples and they were spun at 20,500 $\mathrm{g}$ for $40 \mathrm{~min}$ at room temperature. The pellet was resuspended in $50 \mu \mathrm{L}$ PBS and $1 \mu \mathrm{L}$ anti-Prdx 1-Alexa647, antiPrdx 2-Alexa647 (Antibodies Online), anti-Trx 1-Alexa488 (Novus Biologicals) or isotype control antibodies (Antibodies Online, BD Biosciences) were added. The samples were incubated at room temperature for $20 \mathrm{~min}$. After the incubation period, $450 \mu \mathrm{L}$ PBS and 50 $\mu \mathrm{L}$ latex beads of known concentration were added, and the samples were analysed by flow cytometry as described above.

\section{Statistical analysis}


Statistical analysis was carried out with the GraphPad Prism 6 software (GraphPad Software Inc.). Data were analysed with Kruskal-Wallis test, Mann-Whitney test, paired and unpaired ttests. Results were considered statistically significant if $\mathrm{p}<0.05$.

\section{Results}

Inflammatory stimulation with LPS and TNF results in the upregulation of surface thiol levels on monocytes

The monocytic cell lines U937 and THP1 were used to test the effect of LPS (100 ng/mL, or 1 $\mathrm{ug} / \mathrm{mL}$ ) and TNF (10 ng/mL) treatments (90 minutes) on the level of cell surface thiols. In the case of both U937 (Figure 1 A, D) and Thp1 cells (Figure 1 B, E), exofacial thiol levels increased significantly upon stimulation (unpaired t-test; $\mathrm{p}<0.05$ and one-way ANOVA $\mathrm{p}<0.001$, respectively).

We wanted to test if an elevation of exofacial thiol levels is also inducible on primary monocyte cells. Therefore, in an attempt to model inflammatory conditions ex vivo, we exposed peripheral whole blood samples from HSs $(\mathrm{n}=8)$ to LPS $(100 \mathrm{ng} / \mathrm{mL})$ avoiding exposure of the cells to ambient oxygen. After 90 minutes at $37^{\circ} \mathrm{C}$, exofacial thiol levels were measured. There was a significant increase in the case of LPS-treated primary monocyte samples compared to the control group (paired t-test, p <0.0005) (Figure $1 \mathrm{C}, \mathrm{F}$ ).

\section{Monocytes from rheumatoid arthritis patients show significant elevation in the level of their exofacial thiols compared with monocytes from healthy subjects}

Next, we addressed the question whether monocytes from RA patients showed a difference in their surface thiols as compared to healthy controls. We found monocytes of RA patients to have statistically significantly higher levels of exofacial thiols compared with the monocytes of healthy subjects ( $\mathrm{p}<0.05$, Mann-Whitney test) (Figure $2 \mathrm{C}, \mathrm{F}$ ).

Moreover, we compared surface thiol levels of circulating blood cells in RA patients $(n=15)$ and HS $(\mathrm{n}=10)$. Circulating $\mathrm{CD}^{+} \mathrm{T}$ lymphocytes, $\mathrm{CD} 19^{+} \mathrm{B}$ cells and $\mathrm{CD} 11 \mathrm{c}^{+} / \mathrm{CD} 14^{+}$ 
monocytes have been analysed (Figure 2 A-E) by further labelling them with a thiol-specific fluorescent probe. We found that monocytes had significantly higher surface thiol levels as compared with T lymphocytes in both HS (Figure 1D) and RA (Figure 1E) groups (KruskalWallis test, $\mathrm{p}<0.001, \mathrm{p}<0.0001)$.

\section{The level of exofacial thiols on EVs freshly released by stimulated monocytes is decreased compared with EVs released by unstimulated monocytes}

Having demonstrated that inflammation enhances surface thiol levels on monocytic cells, we wanted to know if similar surface thiol changes also occur on EVs. Therefore, we used in vitro LPS-treated U937 monocyte cells as EV donors, and measured the levels of exofacial thiols in the conditioned media after a 90 min period of incubation (Figure $3 \mathrm{~A}$ ). In line with the finding of decreased thiol levels in RA blood plasma as compared to HS, but in contrast to the increasing levels of cell surface thiols upon inflammatory stimuli, levels of EVs' exofacial thiols also decreased upon LPS stimulation of U937 cells ( $\mathrm{p}<0.05)$. We also analysed this phenomenon in a disease-setting and isolated monocytes from RA patients $(n=6)$ and healthy subjects $(n=5)$. We collected newly released EVs from the isolated cells and measured their surface thiol levels. Similarly to EVs released by stimulated U937 monocyte cells, monocyte cells from RA patients released EVs with a lower exofacial thiol content as compared to EVs released from monocytes of healthy subjects (Figure 3 B) $(p<0.001)$.

The observed lower thiols levels of EVs released from activated monocytes (i.e. in RA patients, and following LPS stimulation) could potentially indicate a mechanism whereby activated cells release EVs low in surface thiols, thereby jettisoning less reduced (oxidised) plasma membrane patches.

\section{Optimisation of thiol-specific labelling of blood plasma-derived extracellular vesicles}

Next, we wanted to test if similar differences could be measured in blood plasma-derived EVs. Although fluorescently labelled maleimide has been proposed by a recent publication to serve as a pan-specific marker of EVs [15], here we found that fluorescently labelled 
maleimide alone was not suitable for labelling plasma-derived EVs due to its large nonspecific, Triton-resistant background noise (Figure 4 A-B). As our earlier work [16] identified low-density lipoprotein (LDL) particles as a potential major source of EV-mimicking events during flow cytometric measurements of blood plasma, we used a commercial preparation of human LDL (Merck) at a physiological concentration $(2 \mathrm{mg} / \mathrm{mL})$ in PBS to test whether it had a mimicking effect in our experimental setup. We stained the LDL preparation with DyLight488 maleimide using the same protocol as for PFP samples. Indeed, LDL particles bound the thiol-reactive dye DyLight-488 maleimide. The labelled events were not removed, but in some cases were even increased following treatment with $0.1 \%$ Triton X-100 (Figure 4 C-D). This was a good indication that LDL interfered with fluorescent maleimide-labelling of circulating vesicles, and suggested that it was necessary to further refine the method of thioldetection on EVs. Therefore, after labelling plasma EVs with fluorescent maleimide, we washed the samples, and added anti-CD9, anti-CD41a or annexin-V, followed by another wash step (Figure 4 E-J). The dually labelled samples were detected using flow cytometry without a significant background noise. The majority of the detected double positive events within the EV gate disappeared after Triton lysis, proving their true vesicular nature (Figure 4 F, H, J).

\section{Redox state of blood plasma-derived extracellular vesicles in healthy subjects and rheumatoid arthritis patients}

After optimising the thiol-specific fluorescent labelling of plasma EVs, we went on to test a range of markers that we expected could detect EVs of different cellular origins in blood plasma. Annexin-V and among the tested antibodies, anti-CD9 and anti-CD41a gave appreciable signals (Figure 5 A-C), while the rest of the antibodies detected only low numbers of events (not shown). Therefore, we carried on with the optimised EV double labelling protocol using DyLight maleimide and either anti-CD9, anti-CD41a or annexin-V. Differential detergent lysis by Triton was used as a control for the vesicular nature of the detected events. Plasma-derived EVs did not display any difference between RA patients and HS in the level of exofacial thiols (Figure 5 D-F). Interestingly, when measuring total plasma thiols (which also include EV thiols), we detected a significant decrease in the thiol levels of 
RA plasma (Figure $5 \mathrm{G}$ ), suggesting oxidation and a decreased reducing power in RA. Although EV populations identified by annexin-V, anti-CD9 and anti-CD41a did not display any differences between patients and controls, our experiment where we measured the thiol levels of EVs dereived from isolated CD14+ cells of RA patients and HS clearly prove that different cell-populations produce EVs with differential thiol distribution.

\section{Exofacial peroxiredoxin $1(\operatorname{Prdx} 1)$ is present on monocytes, Prdx 1 positive EVs are more numerous in RA blood plasma than in healthy controls}

Based on the experiments described so far, it appeared that monocytes were able to enhance their surface reducing power in inflammation at the expense of the reducing power of the released EVs. Therefore, as a next step, we aimed to analyse the distribution of the thiol containing redox protein, peroxiredoxin 1, in the samples. Prdx 1 has a known role in inflammation and autoimmune processes [17], and is also known to be secreted into the blood plasma both as a soluble protein and as a protein associated with exosomes [18].

First, we assessed the presence of $\operatorname{Prdx} 1, \operatorname{Prdx} 2$ or Trx 1 positive EVs in plasma (Figure 6 AC). We found that the blood plasma of both RA patients and health subjects contained such EVs. There was a statistically significantly higher number of Prdx1+ EVs in RA plasma (Figure 6A) (Mann-Whitney test, $\mathrm{p}<0.05$ ). This could not be attributed to a difference in the overall concentration of EVs (Figure 5 A-C). Therefore, we analysed this molecule in downstream experiments. The redox state of Prdx 1 in PBMCs from RA and healthy blood samples was analysed using non-reducing Western blotting. With this approach we found that both the reduced monomeric and the oxidised dimeric forms were present in PBMCs of both groups (Figure 6 D). As to the amount of intracellular Prdx 1 in monocytes, we found no difference between the two subject groups by flow cytometry (Figure $6 \mathrm{G}, \mathrm{I}$ ). Then, we went on to detect exofacial Prdx 1 on monocytes. Using a cell surface protein isolation kit and subsequent Western blotting, we demonstrated the presence of exofacial Prdx 1 in the lysate of U937 cells (Figure 6 E). Furthermore, using flow cytometry, we detected exofacial Prdx 1 on CD14 positive primary monocytes from RA and HS (Figure $6 \mathrm{H}, \mathrm{J}$ ). Almost all CD14 positive cells expressed exofacial Prdx 1 on their surface in both subject groups without a 
significant difference between the two groups (Figure $6 \mathrm{H}$ ).

We also wanted to find out more about the enzymatic potential of the EV-associated Prdxs. Therefore, we used an antibody specific for enzymatically inactive, overoxidised Prdxs. We detected overoxidised Prdx species in EV-enriched 20,500g pellet from blood plasma (Supplementary Figure 1), both in RA patients and HS using Western blotting (Figure 6 F). The fact that we could readily detect overoxidised Prdx in the EV-enriched pellet suggested that a large proportion of EV-associated Prdxs were in fact not active enzymatically. This raises the possibility that EVs function as a "waste disposal" mechanism for enzymatically inactive Prdxs.

\section{Discussion}

Redox processes are crucial regulators of immune responses, and the role that thiol-containing proteins play in cellular signalling is only beginning to be revealed [19]. Similarly, EVs have only recently been recognised as players of cellular communication and immune responses [6]. Although redox processes of EVs have been suggested to be an area of interest [20], so far, only a few sporadic studies have looked into the redox regulation of EVs [8].

Here, we investigated redox aspects of monocytes as well as monocyte-derived and blood plasma-derived EVs. We demonstrated that monocytes displayed elevated exofacial thiol levels under inflammatory conditions such as upon exposure to inflammatory stimuli (LPS or TNF) or during a chronic inflammatory disease such as RA. Exofacial thiols have been shown earlier to associate with lymphocyte activation [2, 3, 21]. An increase in cell surface thiols of monocytes in response to certain contact sensitisers has already been demonstrated [22]. Moreover, this increase in cell surface thiols was suggested to result in intracellular signalling events leading to ER stress [22]. Importantly, proteins of the actin cytoskeletal network were also affected by the sensitiser [22]. Similarly, rearrangement of cytoskeletal proteins such as actin and myosin in response to reduction of cell surface thiol containing proteins was also reported [21]. In addition, EV release by platelets was inhibited by a thiol blocker [7], which also points to the dependence of EV release on surface thiols. Therefore, elevated exofacial 
thiols on RA monocytes are not only markers of activation but may also be a prerequisite for production of EVs just like in the case of platelets [7].

In order to analyse the surface thiol content of EVs, we introduced a new dual labelling approach combining a fluorescent maleimide probe with antibodies to different EV surface markers. We found that fluorescent maleimide alone was not suitable for the specific detection of plasma-derived EVs, due to a large background noise from thiol-containing plasma proteins/protein aggregates and LDL particles. Former publications of our group demonstrated that both plasma protein aggregates and LDL present major confounding factors in the analysis of plasma-derived EVs, and differential detergent lysis provides a tool to distinguish between vesicles and protein aggregates [12]. LDL particles have been shown to be only partially sensitive to detergent lysis [16]. Co-detection of LDL particles can be circumvented by the use of EV-specific markers in addition to maleimide. Here we report that the use of fluorescent maleimide in combination with antibodies to specific EV markers or annexin- $\mathrm{V}$ provide a powerful tool to detect the redox state of plasma EVs. When analysing exofacial thiols of EVs released into the blood plasma, we found no difference between RA patients and HS. LPS stimulation resulted in a significant increase in EV release both by U937 cells [23] and Thp1 cells [24]. In our experiments, upon exposure to LPS, monocytes reacted by increasing their plasma membrane thiols and releasing EVs with decreased surface thiol levels. Also, RA monocytes had higher surface thiol levels compared with healthy monocytes, whilst releasing EVs with a decreased exofacial thiol content. Surface thiols were thus associated with leukocyte activation and proliferation. There is also published information on the molecules involved in directing such redox regulation and their molecular targets [25]. For example, peroxiredoxin $2(\operatorname{Prdx} 2)$ is present on the exofacial surface of $B$ and $\mathrm{T}$ lymphocytes and increased amounts of $\operatorname{Prdx} 2$ have been associated with a Th17 T lymphocyte phenotype [26]. Furthermore, regulatory $\mathrm{T}$ cells express increased exofacial thioredoxin 1 levels in RA and cancer, and also upon in vitro stimulation by TNF [27]. Thus, cell surface thiols of these cells have been suggested to play a protective role and to confer an increase in oxidative stress resistance [27]. The peroxiredoxin family of proteins are known to be associated with inflammation and cellular activation [28], and this is particularly relevant in EV research since peroxiredoxins are known to be present both in the EV cargo [18, 29] 
and as free proteins. In our previous work, Prdx 2 was identified as an upregulated redox protein on the surface of Th17 cells in RA patients [26]. To our knowledge, this present study is the first report to demonstrate the exofacial appearance of $\operatorname{Prdx} 1$ on monocytes. In addition, we found an increased concentration of Prdx 1+ EVs in blood plasma of RA patients as compared to healthy controls. Soluble Prdx 1 has previously been reported to act as a danger signal, and recombinant Prdx 1 was shown to induce an inflammatory response in monocyte cells [30, 31]. Theoretically, Prdx 1 on the surface of EVs could either originate from the releasing cells or from soluble Prdx 1 (in the latter case possibly attached onto the surface of vesicles). In either case, it is possible that similarly to soluble Prdx 1, these Prdx 1+ EVs may serve as danger signals. However, this hypothesis needs to be tested in further experiments.

As to the internal Prdx 1 cargo and redox state of EVs, we observed ,overoxidised” Prdx in EV-enriched preparations from blood plasma. In contrast, no or very little oxeroxidised Prdx could be detected in PBMCs from RA patients and HS (Suppl. Figure 2.). This is in accordance with the observation that mainly oxidised, inactive Prdx 1 is targeted for exosomal release [18], and that overoxidised Prdx gets enriched in the membrane compartment [32]. In fact, it has been described earlier that aggregated, inactive proteins can be cleared from the cells by non-classical secretion [33]. In summary, it appears that EVs have an overall antioxidant role and may well be a marker of oxidative cellular stress.

\section{Conclusion}

In this paper, we show that labelling with fluorescent maleimide is an accurate tool to measure surface thiol content of blood plasma-derived EVs as long as it is used in combination with an EV-specific marker, such as anti-CD9 or annexin-V. Furthermore, here we show for the first time the exofacial appearance of Prdx 1 on monocytes. Our data suggest a novel anti-oxidant protective mechanism via EVs (Figure 7).

\section{Conflict of interest}


The authors declare no conflicts of interest.

\section{Author contributions}

KÉSZT, PGW and EIB conceived the study. KÉSZT, EÁT, AMB, LK, BWS, KP, AN, XO, KVV, MH, ÉP and NF designed and performed experiments. GYN and KP collected samples from blood donors. KÉSZT, EÁT and EIB wrote the manuscript with input from all authors.

\section{Acknowledgements}

This work was supported by the National Scientific Research Program of Hungary (OTKA) grant no. PD 104369 to KSZT, grant no. PD 112085 to VVK and grant no. 111958 and 120237 to EIB, the MEDINPROT Program, BMBS COST Action, the János Bolyai Research Fellowship of the Hungarian Academy of Sciences (to KVV) and the Kerpel Fronius Program of the Semmelweis University (Astellas Pharma Grant to BSW). We are grateful to Prof DA Lawrence (Wadsworth Center, New York State Department of Health, Empire State Plaza, Albany, NY, USA) for helpful communications regarding fluorescent maleimide labelling of leukocytes. Many thanks to Ms Andrea Orbán for skillful assistance in the tissue culture laboratory. We are greatly indebted to all blood donors without whom this study would not have been possible. 


\section{References}

[1] Noelle, R.; Lawrence, D. Modulation of T cell functions. II. Chemical basis for the involvement of cell surface thiol-reactive sites in control of T cell proliferation. Cellular Immunology 60:453-469; 1981.

[2] Pellom, S. T.; Michalek, R. D.; Crump, K. E.; Langston, P. K.; Juneau, D. G.; Grayson, J. M. Increased Cell Surface Free Thiols Identify Effector CD8+ T Cells Undergoing T Cell Receptor Stimulation. PLOS ONE 8:e81134; 2013.

[3] Lawrence, D. A.; Song, R.; Weber, P. Surface thiols of human lymphocytes and their changes after in vitro and in vivo activation. Journal of Leukocyte Biology 60:611-618; 1996.

[4] Gelderman, K. A.; Hultqvist, M.; Holmberg, J.; Olofsson, P.; Holmdahl, R. T cell surface redox levels determine $T$ cell reactivity and arthritis susceptibility. Proceedings of the National Academy of Sciences 103:12831-12836; 2006.

[5] György, B.; Szabó, T.; Pásztói, M.; Pál, Z.; Misják, P.; Aradi, B.; László, V.; Pállinger, É.; Pap, E.; Kittel, Á.; Nagy, G.; Falus, A.; Buzás, E. Membrane vesicles, current state-of-the-art: emerging role of extracellular vesicles. Cellular and Molecular Life Sciences 68:2667-2688; 2011.

[6] Buzás, E. I.; György, B.; Nagy, G.; Falus, A.; Gay, S. Emerging role of extracellular vesicles in inflammatory diseases. Nature Reviews Rheumatology 10:356-364; 2014.

[7] Dachary-Prigent, J.; Freyssinet, J. M.; Pasquet, J. M.; Carron, J. C.; Nurden, A. T. Annexin V as a probe of aminophospholipid exposure and platelet membrane vesiculation: a flow cytometry study showing a role for free sulfhydryl groups. Blood 81:2554-2565; 1993.

[8] Szabó-Taylor, K.; Ryan, B.; Osteikoetxea, X.; Szabó, T. G.; Sódar, B.; Holub, M.; Németh, A.; Pálóczi, K.; Pállinger, É.; Winyard, P.; Buzás, E. I. Oxidative and other posttranslational modifications in extracellular vesicle biology. Seminars in Cell \& Developmental Biology 40:8-16; 2015.

[9] György, B.; Pálóczi, K.; Kovács, A.; Barabás, E.; Bekő, G.; Várnai, K.; Pállinger, É.; Szabó-Taylor, K.; Szabó, T. G.; Kiss, A. A.; Falus, A.; Buzás, E. I. Improved circulating microparticle analysis in acidcitrate dextrose (ACD) anticoagulant tube. Thrombosis Research 133:285-292; 2013.

[10] Aletaha, D.; Neogi, T.; Silman, A. J.; Funovits, J.; Felson, D. T.; Bingham, C. O., 3rd; Birnbaum, N. S.; Burmester, G. R.; Bykerk, V. P.; Cohen, M. D.; Combe, B.; Costenbader, K. H.; Dougados, M.; Emery, P.; Ferraccioli, G.; Hazes, J. M.; Hobbs, K.; Huizinga, T. W.; Kavanaugh, A.; Kay, J.; Kvien, T. K.; Laing, T.; Mease, P.; Menard, H. A.; Moreland, L. W.; Naden, R. L.; Pincus, T.; Smolen, J. S.; Stanislawska-Biernat, E.; Symmons, D.; Tak, P. P.; Upchurch, K. S.; Vencovsky, J.; Wolfe, F.; Hawker, G. 2010 Rheumatoid arthritis classification criteria: an American College of Rheumatology/European League Against Rheumatism collaborative initiative. Arthritis Rheumatism 62:2569-2581; 2010.

[11] Aletaha, D.; Neogi, T.; Silman, A. J.; Funovits, J.; Felson, D. T.; Bingham, C. O., 3rd; Birnbaum, N. S.; Burmester, G. R.; Bykerk, V. P.; Cohen, M. D.; Combe, B.; Costenbader, K. H.; Dougados, M.; Emery, P.; Ferraccioli, G.; Hazes, J. M.; Hobbs, K.; Huizinga, T. W.; Kavanaugh, A.; Kay, J.; Kvien, T. K.; Laing, T.; Mease, P.; Menard, H. A.; Moreland, L. W.; Naden, R. L.; Pincus, T.; Smolen, J. S.; Stanislawska-Biernat, E.; Symmons, D.; Tak, P. P.; Upchurch, K. S.; Vencovsky, J.; Wolfe, F.; Hawker, G. 2010 Rheumatoid arthritis classification criteria: an American College of Rheumatology/European League Against Rheumatism collaborative initiative. Annals of Rheumatic Diseases 69:1580-1588; 2010.

[12] György, B.; Módos, K.; Pállinger, É.; Pálóczi, K.; Pásztói, M.; Misják, P.; Deli, M. A.; Sipos, Á.; Szalai, A.; Voszka, I.; Polgár, A.; Tóth, K.; Csete, M.; Nagy, G.; Gay, S.; Falus, A.; Kittel, Á.; Buzás, E. I. Detection and isolation of cell-derived microparticles are compromised by protein complexes resulting from shared biophysical parameters. Blood 117:e39-e48; 2011.

[13] Osteikoetxea, X.; Balogh, A.; Szabó-Taylor, K.; Németh, A.; Szabó, T. G.; Pálóczi, K.; Sódar, B.; 
Kittel, Á.; György, B.; Pállinger, É.; Matkó, J.; Buzás, E. I. Improved Characterization of EV Preparations Based on Protein to Lipid Ratio and Lipid Properties. PLOS ONE 10:e0121184; 2015.

[14] Poynton, R. A.; Hampton, M. B. Peroxiredoxins as biomarkers of oxidative stress. Biochimica et Biophysica Acta 1840:906-912; 2013.

[15] Headland, S. E.; Jones, H. R.; D'Sa, A. S. V.; Perretti, M.; Norling, L. V. Cutting-Edge Analysis of Extracellular Microparticles using ImageStreamX Imaging Flow Cytometry. Scientific Reports 4:5237; 2014.

[16] Sódar, B. W.; Kittel, Á.; Pálóczi, K.; Vukman, K. V.; Osteikoetxea, X.; Szabó-Taylor, K.; Németh, A.; Sperlágh, B.; Baranyai, T.; Giricz, Z.; Wiener, Z.; Turiák, L.; Drahos, L.; Pállinger, É.; Vékey, K.;

Ferdinándy, P.; Falus, A.; Buzás, E. I. Low-density lipoprotein mimics blood plasma-derived exosomes and microvesicles during isolation and detection. Scientific Reports 6:24316; 2016.

[17] Szabó, K. É.; Gutowski, N. J.; Holley, J. E.; Littlechild, J. A.; Winyard, P. G. Redox control in human disease with a special emphasize on the peroxiredoxin-based antioxidant system. In: Jacob, C.; Winyard, P. G., eds. Redox signalling and regulation in biology and medicine. Weinheim: Wiley$\mathrm{VCH} ; 2009:$ 409-431.

[18] Mullen, L.; Hanschmann, E.-M.; Lillig, C. H.; Herzenberg, L. A.; Ghezzi, P. Cysteine Oxidation Targets Peroxiredoxins 1 and 2 for Exosomal Release through a Novel Mechanism of RedoxDependent Secretion. Molecular Medicine. 21:98-108; 2015.

[19] Sobotta, M. C.; Liou, W.; Stocker, S.; Talwar, D.; Oehler, M.; Ruppert, T.; Scharf, A. N.; Dick, T. P. Peroxiredoxin-2 and STAT3 form a redox relay for $\mathrm{H}_{2} \mathrm{O}_{2}$ signaling. Nature Chemical Biology 11:6470; 2015.

[20] Griffiths, H. R.; Dias, I. H. K.; Willetts, R. S.; Devitt, A. Redox regulation of protein damage in plasma. Redox Biology 2:430-435; 2014.

[21] Laragione, T.; Bonetto, V.; Casoni, F.; Massignan, T.; Bianchi, G.; Gianazza, E.; Ghezzi, P. Redox regulation of surface protein thiols: identification of integrin alpha- 4 as a molecular target by using redox proteomics. Proceedings of the National Academy of Sciences of the USA 100:14737-14741; 2003.

[22] Hirota, M.; Motoyama, A.; Suzuki, M.; Yanagi, M.; Kitagaki, M.; Kouzuki, H.; Hagino, S.; Itagaki, H.; Sasa, H.; Kagatani, S.; Aiba, S. Changes of cell-surface thiols and intracellular signaling in human monocytic cell line THP-1 treated with diphenylcyclopropenone. The Journal of Toxicological Sciences 35:871-879; 2010.

[23] Xie, G. L.; Nomura, S.; Fukuhara, S. Annexin V Expression and Membrane Vesiculation during Activation of Leukemic Cell Lines. Pathophysiology of Haemostasis and Thrombosis 27:259-268; 1997. [24] Bernimoulin, M.; Waters, E. K.; Foy, M.; Steele, B. M.; Sullivan, M.; Falet, H.; Walsh, M. T.; Barteneva, N.; Geng, J. G.; Hartwig, J. H.; Maguire, P. B.; Wagner, D. D. Differential stimulation of monocytic cells results in distinct populations of microparticles. Journal of Thrombosis and Haemostasis 7:1019-1028; 2009.

[25] Szabó-Taylor, K. É.; Nagy, G.; Eggleton, P.; Winyard, P. Oxidative Stress in Rheumatoid Arthritis. In: Alcaraz, M. J.; Gualillo, O.; Sánchez-Pernaute, O., eds. Studies on Arthritis and Joint Disorders: Springer New York; 2013: 145-167.

[26] Szabó-Taylor, K. E.; Eggleton, P.; Turner, C. A.; Faro, M. L.; Tarr, J. M.; Tóth, S.; Whiteman, M.; Haigh, R. C.; Littlechild, J. A.; Winyard, P. G. Lymphocytes from rheumatoid arthritis patients have elevated levels of intracellular peroxiredoxin 2 , and a greater frequency of cells with exofacial peroxiredoxin 2, compared with healthy human lymphocytes. International Journal of Biochemistry and Cell Biology 44:1223-1231; 2012.

[27] Mougiakakos, D.; Johansson, C. C.; Jitschin, R.; Böttcher, M.; Kiessling, R. Increased thioredoxin-1 production in human naturally occurring regulatory $T$ cells confers enhanced tolerance 
to oxidative stress. Blood 117:857-861; 2011.

[28] Szabó, K. É.; Line, K.; Eggleton, P.; Littlechild, J. A.; Winyard, P. G. Structure and function of the human peroxiredoxin-based antioxidant system: the interplay between peroxiredoxins,

thioredoxins, thioredoxin reductases, sulfiredoxins and sestrins. In: Winyard, P. G.; Jacob, C., eds. Redox signalling and regulation in biology and medicine. Weinheim: Wiley-VCH; 2009: 143-179.

[29] Turiák, L.; Misják, P.; Szabó, T. G.; Aradi, B.; Pálóczi, K.; Ozohanics, O.; Drahos, L.; Kittel, Á.; Falus, A.; Buzás, E. I.; Vékey, K. Proteomic characterization of thymocyte-derived microvesicles and apoptotic bodies in BALB/c mice. Journal of Proteomics 74:2025-2033; 2011.

[30] Riddell, J. R.; Wang, X.-Y.; Minderman, H.; Gollnick, S. O. Peroxiredoxin 1 Stimulates Secretion of Pro-Inflammatory Cytokines by Binding to Toll-like Receptor 4. Journal of immunology 184:10221030; 2010.

[31] Tae Lim, Y.; Sup Song, D.; Joon Won, T.; Lee, Y.-J.; Yoo, J.-S.; Eun Hyung, K.; Won Yoon, J.; Park, S.-Y.; Woo Hwang, K. Peroxiredoxin-1, a possible target in modulating inflammatory cytokine production in macrophage like cell line RAW264.7. Microbiology and Immunology 56:411-419; 2012. [32] Schröder, E.; Brennan, J. P.; Eaton, P. Cardiac peroxiredoxins undergo complex modifications during cardiac oxidant stress. American Journal of Physiology - Heart and Circulatory Physiology 295:H425-H433; 2008.

[33] Tanudji, M.; Hevi, S.; Chuck, S. L. Improperly folded green fluorescent protein is secreted via a non-classical pathway. Journal of Cell Science 115:3849-3857; 2002. 
Figure Captions

Fig. 1. Changes in surface thiol levels of monocytes upon in vitro and ex vivo stimulation with LPS and TNF. A) Increase in the exofacial thiol levels of U937 monocyte cells upon stimulation with LPS $(100 \mathrm{ng} / \mathrm{mL})$ (unpaired t test $\mathrm{p}<0.05)$. B) Increase in the exofacial thiol levels of Thp1 monocyte cells upon stimulation with LPS or TNF (one-way ANOVA with Dunnett's post test, $p<0.001$, post-test: $\mathrm{p}<0.01)$. C) Increase in the surface thiol levels of primary monocytes stimulated with LPS in whole blood ex vivo (paired t test, $\mathrm{p}<0.0005$ ). D), E), F) representative histograms of the surface thiol levels of the respective cells in the top panels. (untreated controls: light grey, LPS and TNF treatments: black or transparent). Continuous line: 100ng/mL LPS; dotted line: $1 \mu \mathrm{g} / \mathrm{mL}$ LPS; dashed line: $10 \mathrm{ng} / \mathrm{mL}$ TNF

Fig. 2. $\mathrm{CD} 11 \mathrm{c}^{+} / \mathrm{CD}^{+} 4^{+}, \mathrm{CD}^{+}{ }^{+}$and $\mathrm{CD3}^{+}$leukocytes show significant differences in the level of exofacial thiols. A, B, C) Levels of surface thiols of peripheral blood T cells, B cells and monocytes, respectively, from healthy subjects (HS) and RA patients (RA). MannWhitney test $(\mathrm{p}<0.05)$. D, E) Levels of surface thiols of peripheral blood cells from healthy subjects (D) and RA patients (E) presented as MFI of DyLight-488 Mal (arbitrary value). Kruskal-Wallis test with Dunn's post test, $(\mathrm{p}<0.001, \mathrm{p}<0.0001)$. F) Representative histogram of DyLight-488 Mal staining of monocytes from a healthy subject (light grey) and an RA patient (black).

Fig. 3. Thiols on the surface of monocyte derived EVs ex vivo and in vitro A) U937 cells were incubated with $100 \mathrm{ng} / \mathrm{mL}$ LPS, and thiol levels of the released EVs were measured in the conditioned medium after a 90 minute period ( $t$ test, $\mathrm{p}<0.05$ ). B) Monocytes were isolated from RA patients and healthy subjects and incubated for 90 minutes after which the released EVs' thiol levels were measured using flow cytometry. (Mann-Whitney test, p<0.01). C) A representative dot-plot of the EVs released by isolated monocytes. 
Fig.4. Representative dot-plots of RA PFP samples or LDL solution before and after the addition of 0.1\% Triton-X100. A) and B) show single DyLight maleimide staining of PFP. C) and D) show single DyLight maleimide staining of LDL. E)-J) show samples labelled with DyLight maleimide in combination with anti-CD9 antibody, anti-CD41a antibody or annexin- $\mathrm{V}$.

Fig. 5. Thiols on the surface of EVs and in blood plasma. Single labelling of PFPs from RA patients and HS with anti-CD9 (A), anti-CD41a (B), and annexin-V (C), respectively. Dual labelling of PFPs from RA patients and HS with a fluorescent maleimide probe and antiCD9 (D), anti-CD41a (E) or annexin-V (F), respectively. G) Thiols in PFPs measured using an Ellman's assay (Mann-Whitney test, p<0.0001).

Fig. 6. Peroxiredoxin 1, 2 and thioredoxin 1 on blood plasma EVs, exofacial and intracellular peroxiredoxin 1 of PBMCs. A) The concentration of Prdx $1+$ EVs in RA $(n=24)$ and HS ( $n=16)$ plasma, detected using flow cytometry (Mann-Whitney test $\mathrm{p}<0.05)$. B) The concentration of Prdx 2+ EVs in RA (n=9) and HS $(n=7)$ plasma, detected using flow cytometry. C) The concentration of Trx 1+ EVs in RA (n=6) and HS (n=6) plasma, detected using flow cytometry. D) PBMC lysates from RA patients $(\mathrm{n}=8)$ and HS $(\mathrm{n}=5)$ were resolved on non-reducing gels and detected with an anti-Prdx 1 antibody. Oxidised dimeric and reduced monomeric forms were equally present in both subject groups. E) The presence of exofacial Prdx 1 was demonstrated on U937 monocytes using a cell surface protein isolation kit and Western blotting. A lysate of PBMCs was used as a positive control for Prdx 1, and detection of protein disulfide isomerase (PDI) in the membrane extracts was used as positive control to confirm the presence of membrane proteins. F) The oxidation state of Prdxs in EVenriched pellets from blood plasma were analysed using an antibody specific for "overoxidised" Prdxs. G) The intracellular presence of Prdx 1 in CD14 ${ }^{+}$monocytes from RA $(n=10)$ and HS $(n=11)$ were measured by flow cytometry. H) The exofacial distribution of 
$\operatorname{Prdx} 1$ in $\mathrm{CD}_{1} 4^{+}$monocytes from RA $(\mathrm{n}=10)$ and HS $(\mathrm{n}=14)$ were measured by flow cytometry. I) Representative histogram of an RA sample. Light grey histogram shows the isotype control, dark grey histogram shows intracellular staining for Prdx 1 in CD14 ${ }^{+}$cells. J) A corresponding representative histogram of a PBMC sample (from an RA patient). Light grey histogram shows the isotype control, dark grey histogram shows intracellular staining for Prdx 1 in CD14 ${ }^{+}$cells.

Fig. 7. Proposed model for the disposal of oxidised/less reduced membrane patches and oxidised molecules via EVs. SH designates thiol groups on surface proteins, S-S designates disulfides, Prdx 1-SH stands for reduced (thiol-containing) Prdx 1 and $\operatorname{Prdx} 1-\mathrm{SO}_{2}$ designates overoxidised Prdx 1 (sulphinic peroxiredoxin). 


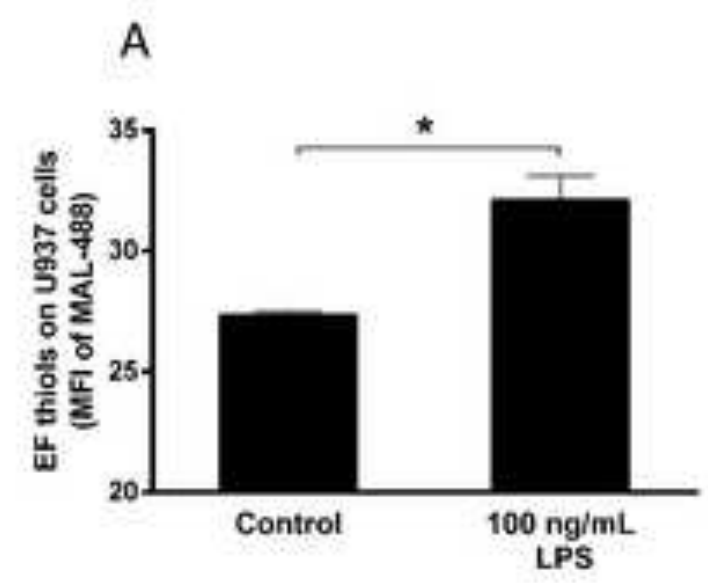

D

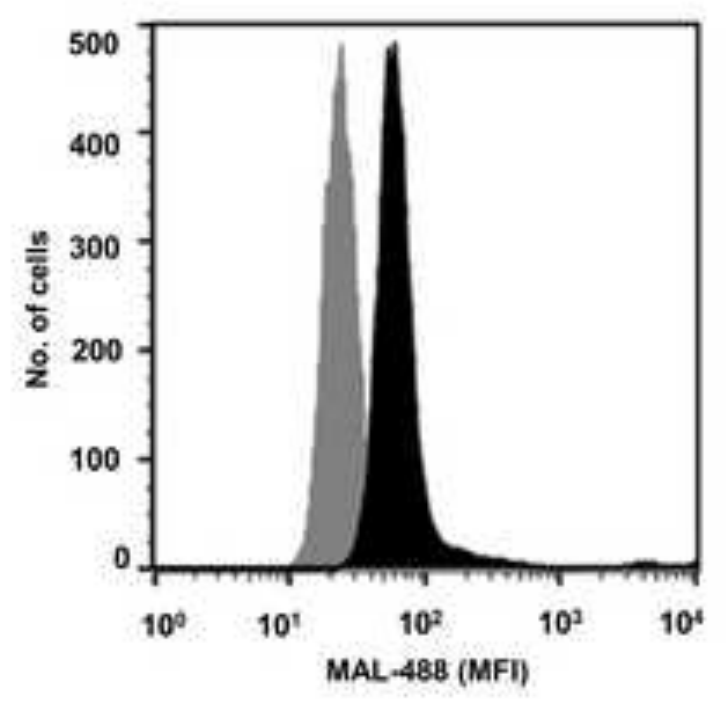

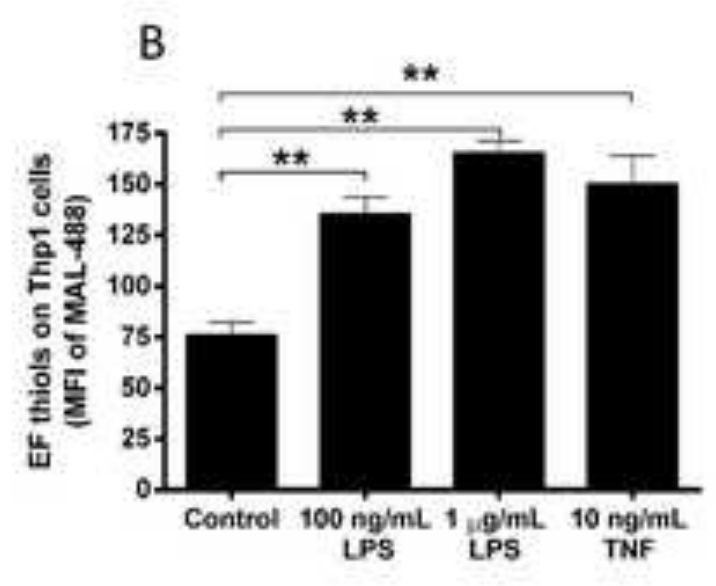

E

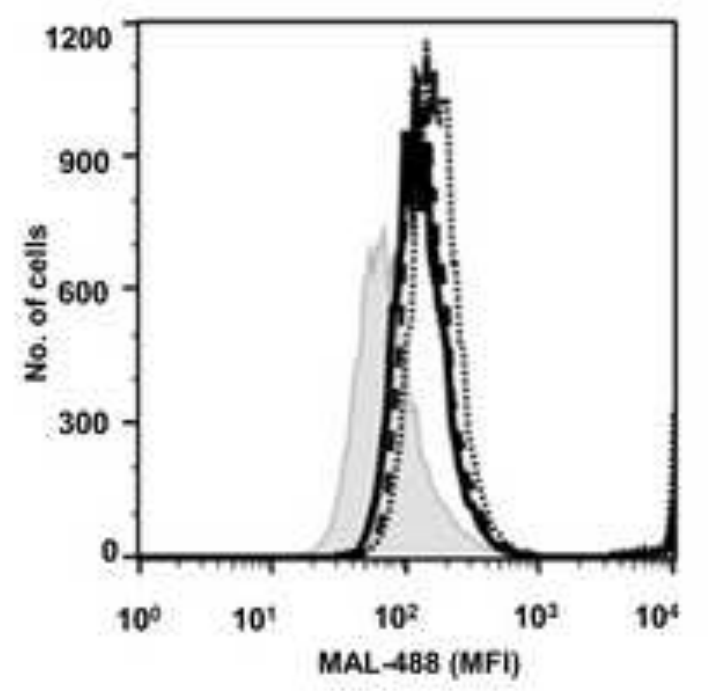

C

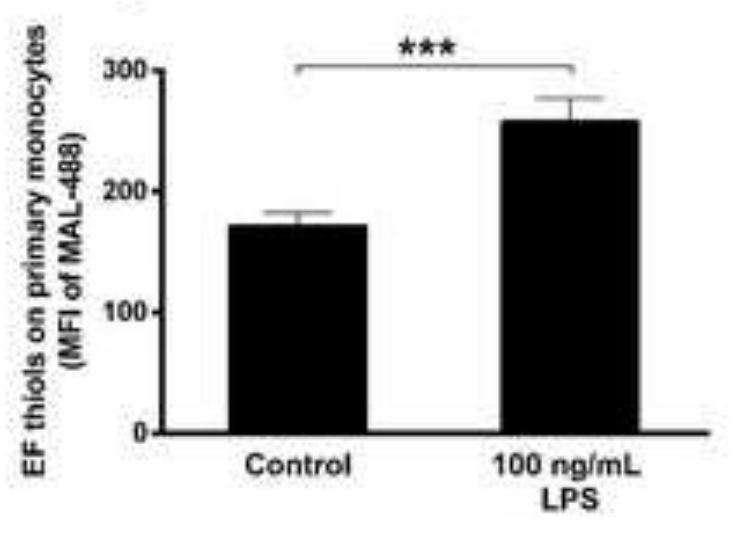

F

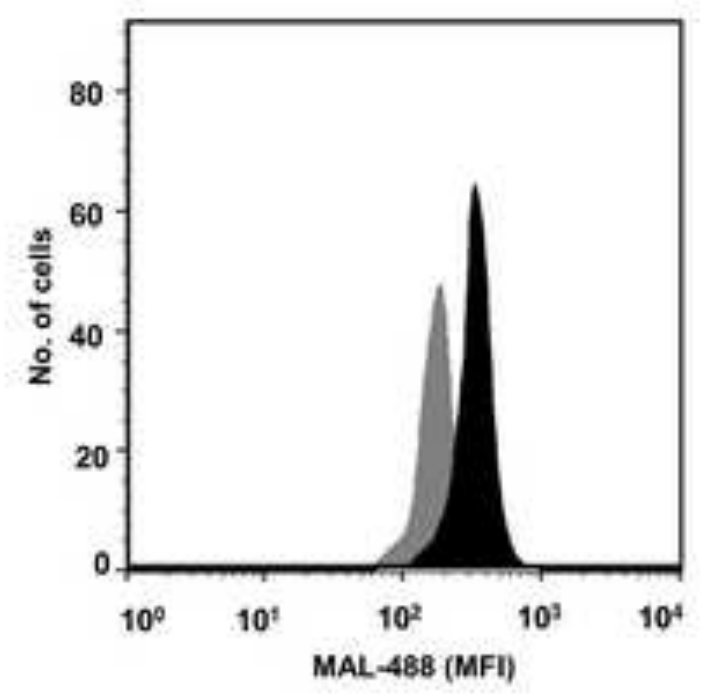


Click here to download high resolution image
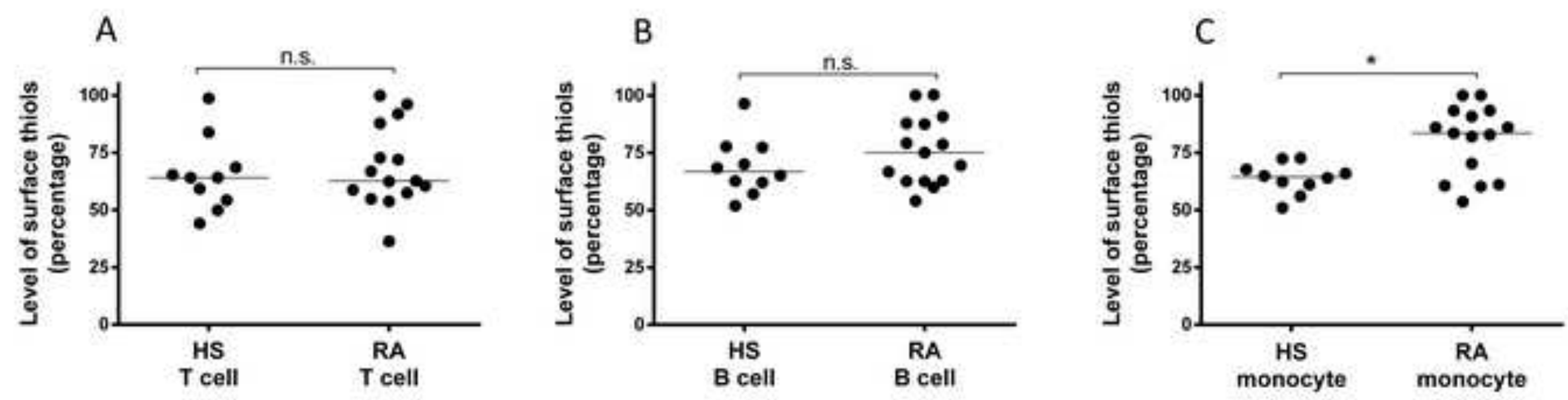

D
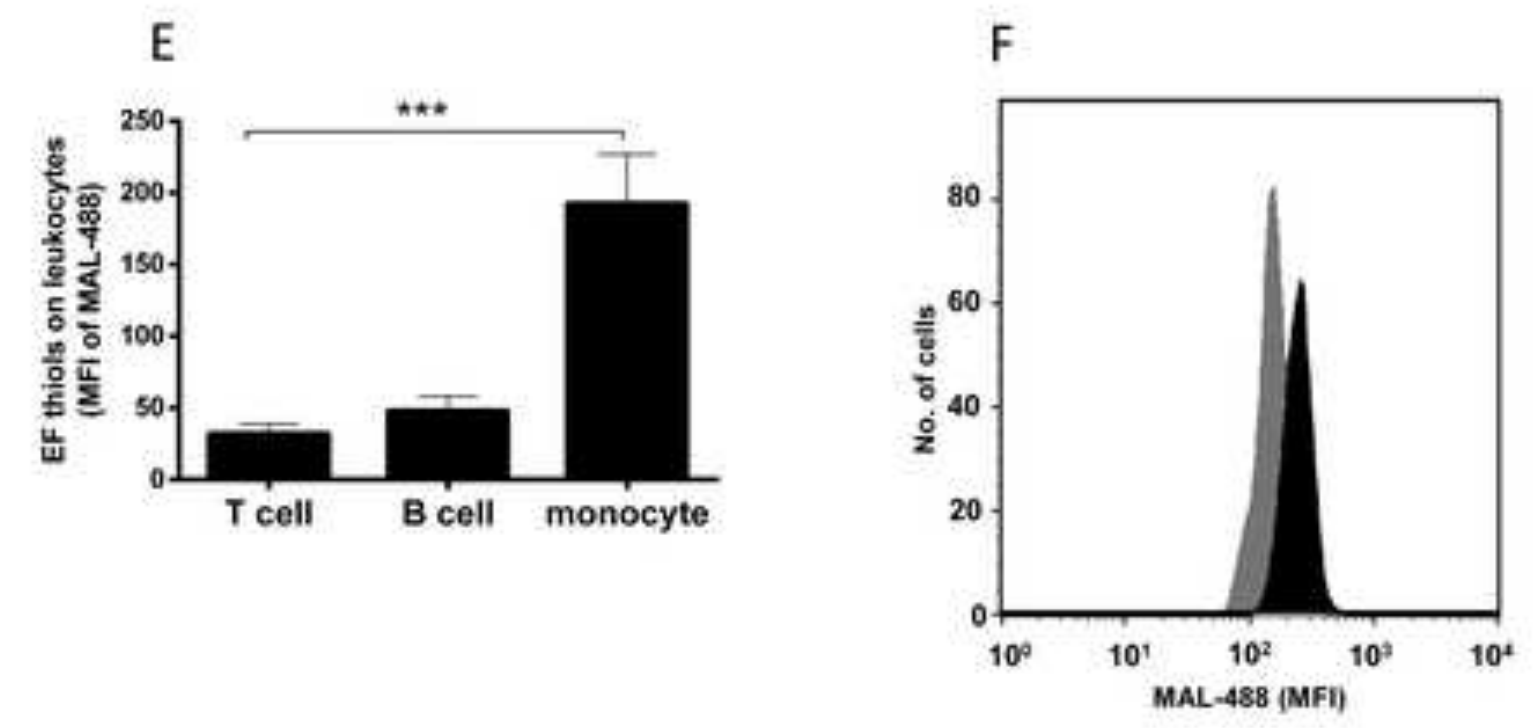

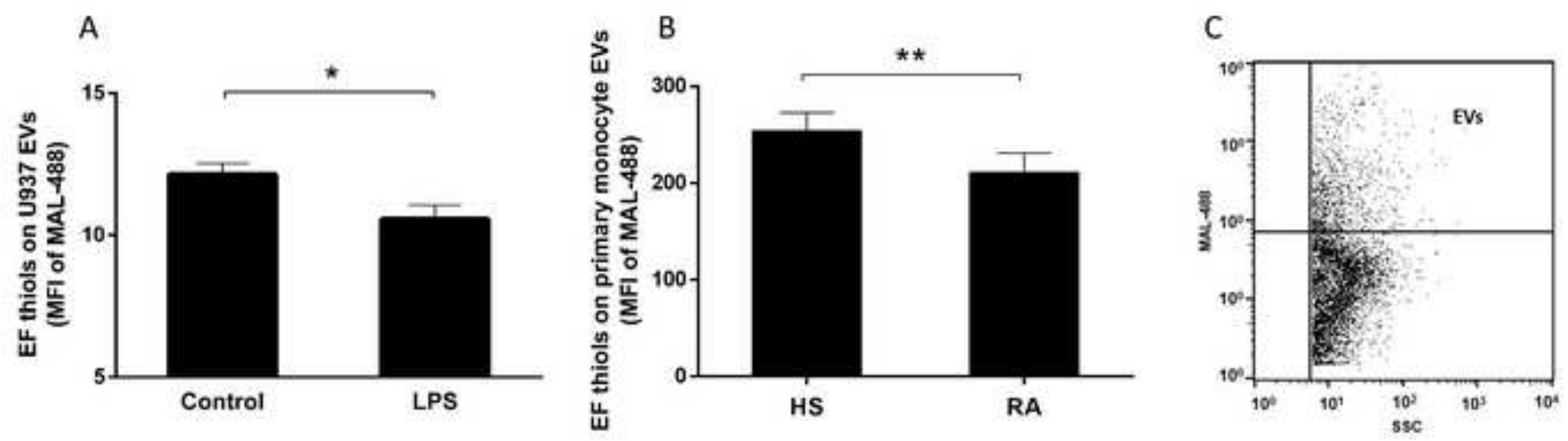


\section{Single-labelling with MAL- 488}
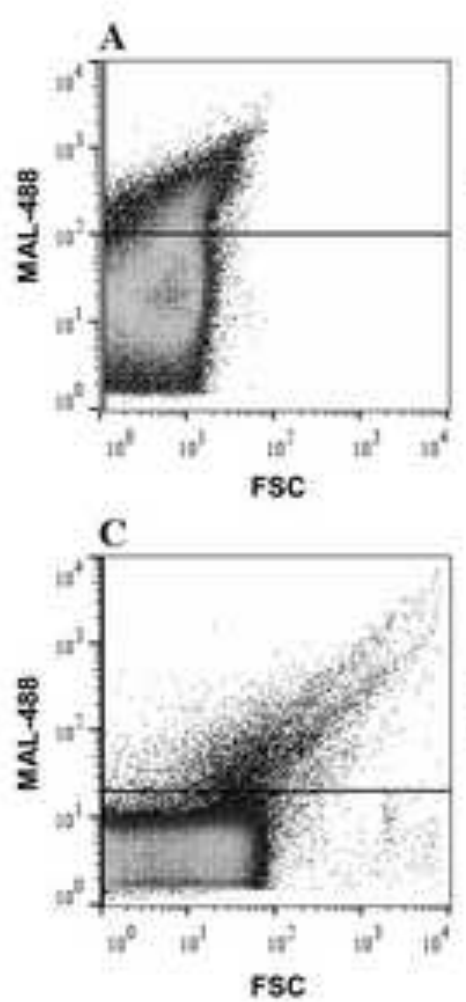

Plasma

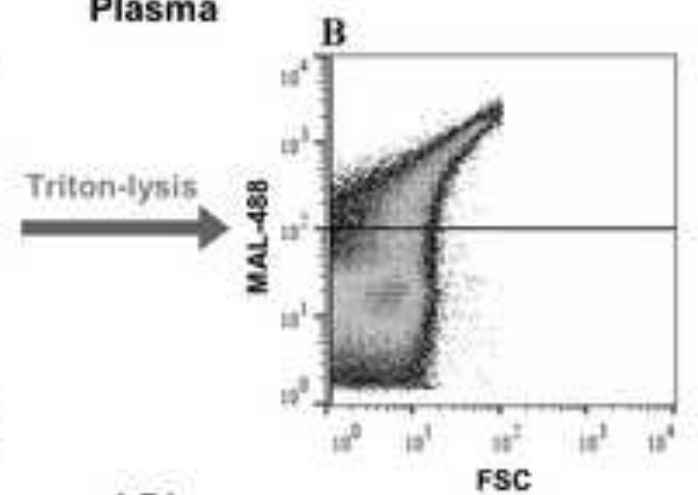

LDL

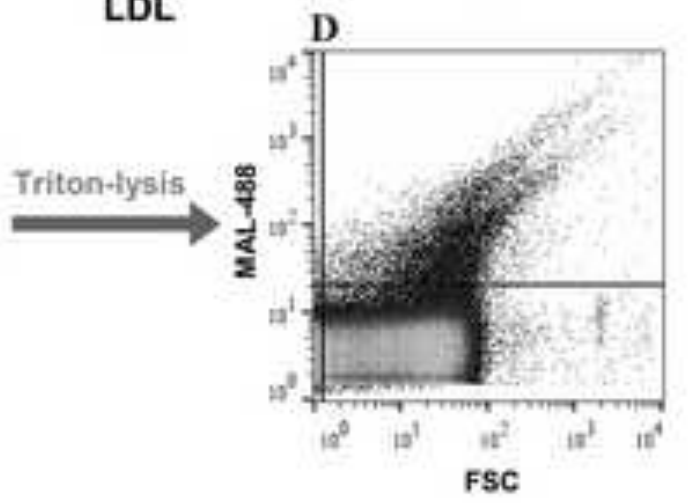

Double-labelling with MAL-488/-633 and vesicle specific markers
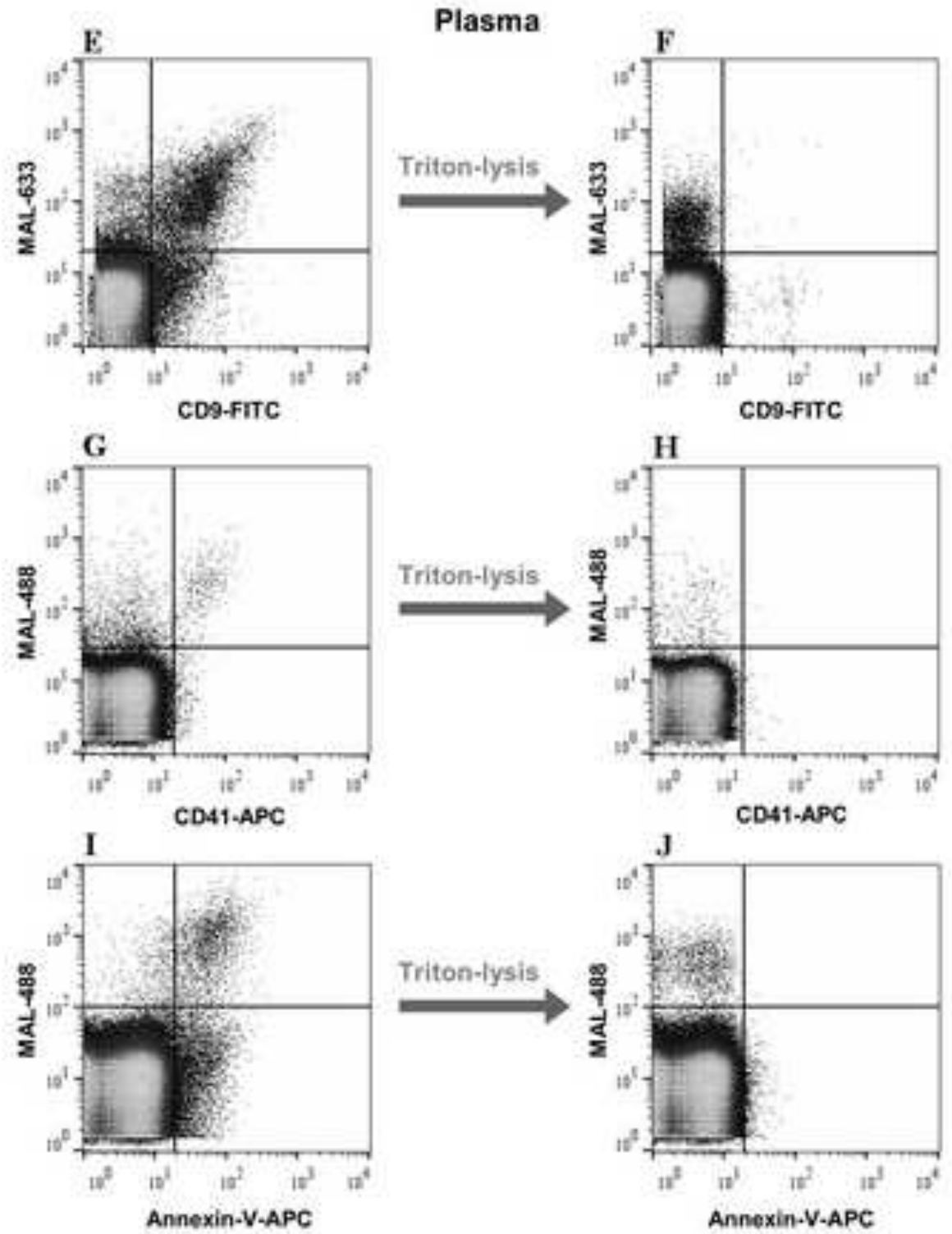
Click here to download high resolution image
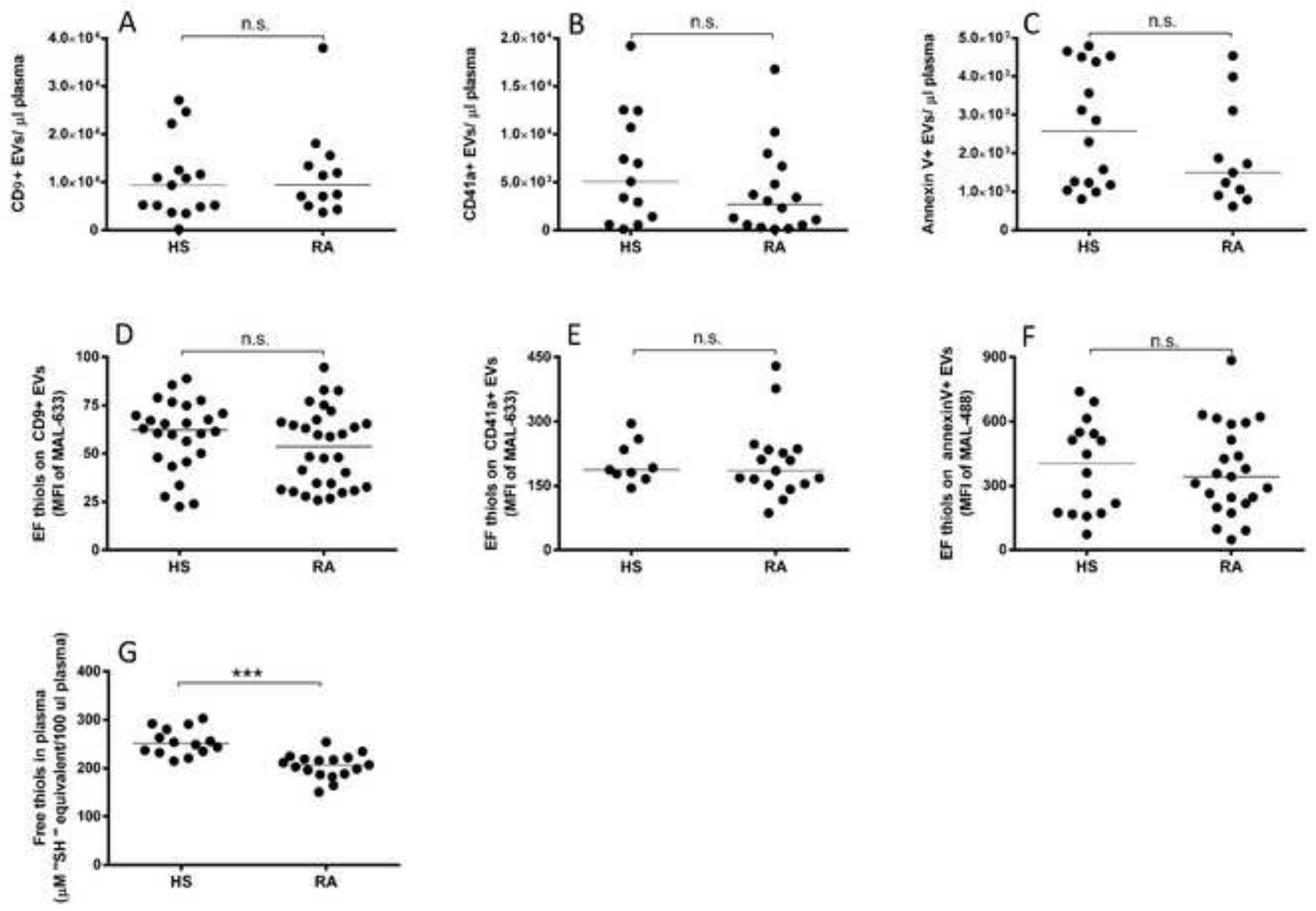

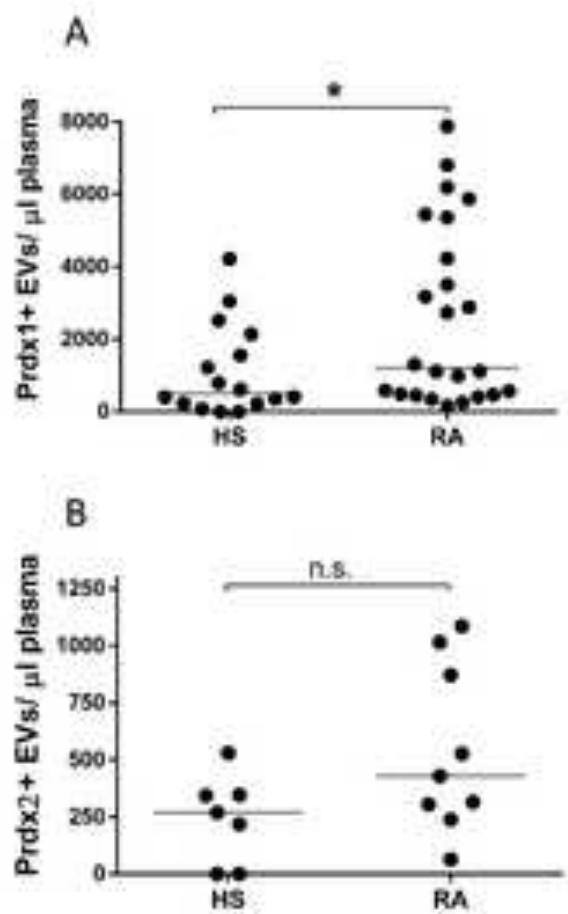

C

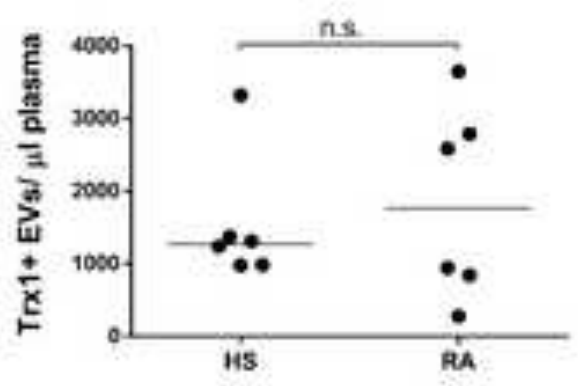

D RAPBMC HSPBMC

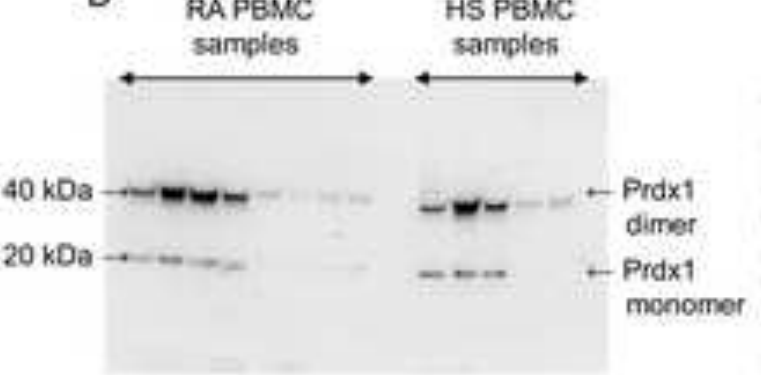

Intracellular Prdx 1

E

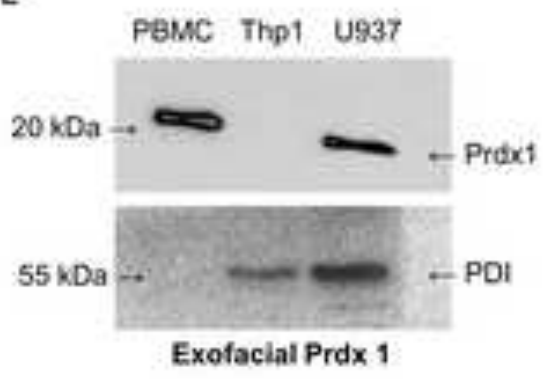

F

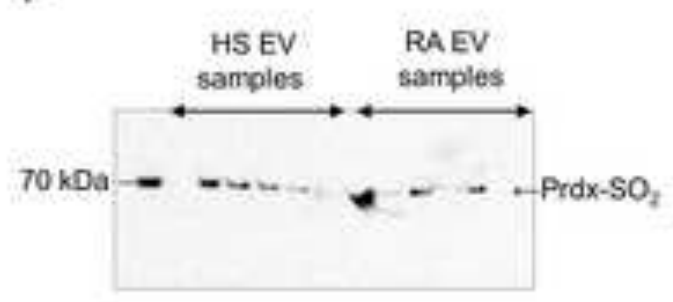

G
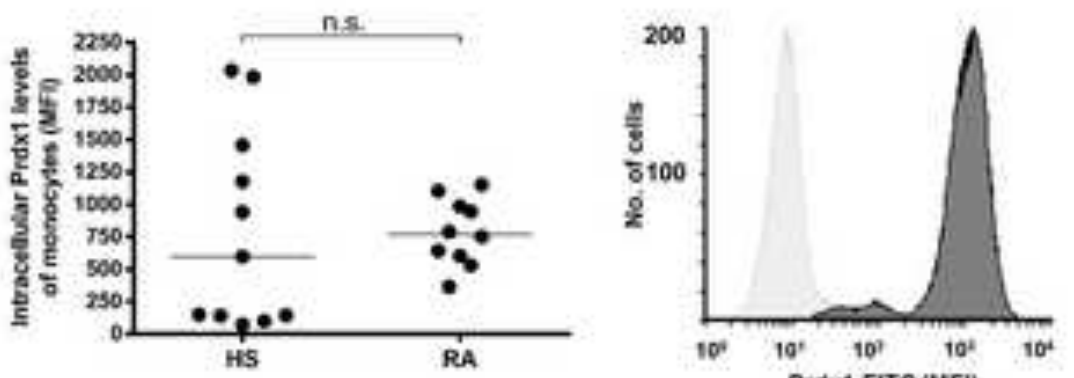

Proxi-FITC (MFI)

H
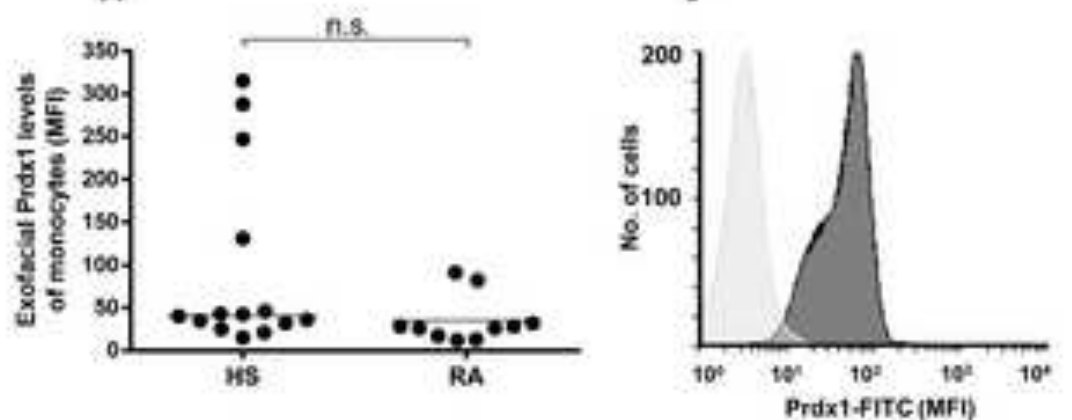

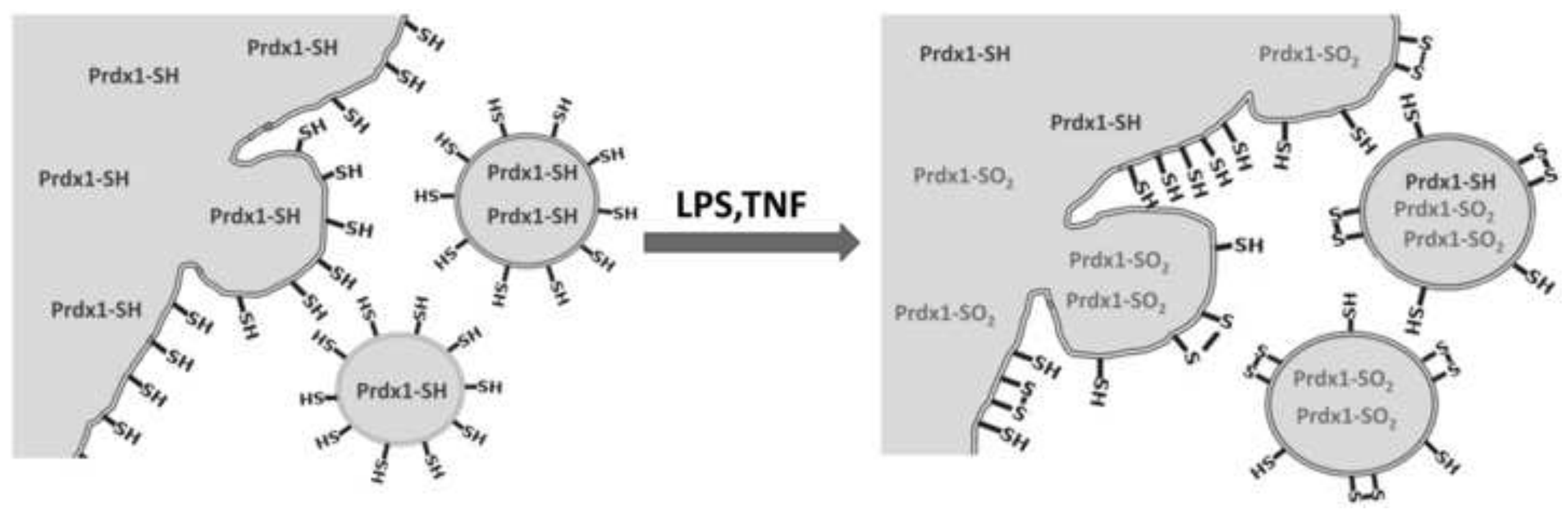
Supplementary Material

Click here to download Supplementary Material: Supplementary figures Szabo-Taylor and Toth et al.docx

\begin{abstract}
Ch here to download Supplementary Material: Supplementary figures Szabo-Taylor and Toth et aldocx.
\end{abstract}

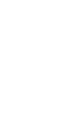

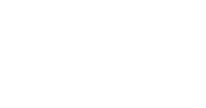

